\title{
Health and environment: a changing paradigm in the Covid 19 era
}

\author{
Annalaura Carducci
}

Publisher's Note: MDPI stays neutral with regard to jurisdictional claims in published maps and institutional affiliations.

\section{(c) (i)}

Copyright: (c) 2020 by the authors. Submitted for possible open access publication under the terms and conditions of the Creative Commons Attribution (CC BY) license (http://creativecommons.org/licenses /by/4.0/).

\begin{abstract}
The COVID-19 pandemic has deeply impacted our relationship with the environment and the achievement of sustainable development goals, sometimes in opposite ways. The emergence of SARS-CoV-2 has demonstrated the urgent need to adopt the "one health" approach in every future action involving health and the environment, and its spread has highlighted the importance of research about the environmental determinants of its transmission. Increasing knowledge about the virus' presence in different environmental matrices and conditions is revealing the significant diffusion of its RNA, although its actual viability in these circumstances remains to be demonstrated. Moreover, some epidemiological findings suggest that environmental conditions may be associated with the spread and related mortality of the virus. COVID-19 prevention still relies on measures linked to the environment: the use of masks, social distancing, hygiene and disinfection. On the other hand, some of these measures can exacerbate environmental pollution, such as increased waste (gloves and masks) and generalized use of disinfectants: this can produce an apparent conflict of interest between the infective and chemical risks. Therefore, the COVID-19 pandemic should change our approach to environmental risk assessment, focusing not only on chemicals but also on biological agents, with the analysis and comparison of these substances through quantitative methods. Efforts made toward recovering from the socio-economic impact of the pandemic should also be focused on environmental preservation and protection. In conclusion, the pandemic provides us with the opportunity to rethink the coupling of health and the environment from a wider and more comprehensive perspective.
\end{abstract}

Keywords: health and environment; COVID-19; one health approach; environmental transmission; chemical and biological risk assessment 